\title{
Current Situation and Countermeasures of Physical Training in Volleyball Training
}

\author{
Yang Sun ${ }^{1}$, Yuehong $\mathrm{Ma}^{2}$ \\ ${ }^{1}$ Heilongjiang University of Technology, Jixi, 158100, China \\ ${ }^{2}$ Mudanjiang Normal University, Mudanjiang, 157012, China
}

\begin{abstract}
At present, a volleyball athlete's physical training is an important part of a volleyball athlete's education, as well as a compulsory course of the training of modern volleyball talents. Firstly, this paper introduces the concept of volleyball physical training. Then, it analyses existing problems of the physical training in the volleyball training, such as the little physical training time, single physical training model and the unreasonable physical training content. Finally, this paper gives the corresponding countermeasures and suggestions to provide some references for the relevant researchers.
\end{abstract}

Keywords: physical training, volleyball training, current situation and countermeasures

\section{Concept of Physical Training}

With the continuous development of volleyball technology and tactics, the men and women volleyball teams' offensive tactics in the world has profoundly changed, such as jumping service and back row attack tactics, major changes in these tactics, make speed more and more quickly, more and more power. And the implementation of these techniques and tactics require athletes to have a superb technology, flexible use of various tactical capabilities, as well as good physical ability. It can be said that the competition of physical fitness is becoming the new focus of volleyball competition. Especially after the implementation of eachserve-a-point rule rules, competition intensity and difficulty increase, which puts forward higher requirements on the athletes' physical fitness. The community has not given a consistent definition of physical fitness. From the broad perspective, 
with the connotation of physical fitness, it refers to a person's physical quality, sports skills and physical form; in a narrow sense, physical fitness is acquired through exercise athletes' physical fitness. But, in general, physical fitness mainly consists of two parts, which are the innate ability of activity and the acquired physical quality. And physical training is to develop their functional capacity and physical factors, the long-time of high load capacity training. Physical fitness training aims to make the body organs and skills system through the overload of training to produce physical adaptation and psychological adaptation, to achieve the goal of mining their own functional potential, improve the ability to exercise.

\section{Existing Problems of Physical Training in Volleyball Training}

\subsection{Little physical training time}

In our country, the importance of physical training of volleyball is not mainly reflected in the allocation of teachers, the emphasis on the tactical training and the lack of three aspects of theoretical research of volleyball. First, the teacher is not reasonable configuration. At present, China's volleyball coaches division of labor is not clear, most of a number of training, not specific to the reasonable elements, daily life management etc. a coach is responsible for tactical training, physical training and the team is very common. Second, although most coaches think that physical fitness training as a separate training program, but in reality, they always focus on tactical training, and the physical training of a pen with a. The last is the lack of special research on the physical training of volleyball. Although there are some researches on physical fitness training in sports in our country, there are few studies on the physical training of volleyball. In the physical training to have the good order of reason, students do not be late, do not leave early, not just listen to the whistle sound absent; immediately stop training. If any bad behavior is found, immediately give persuasion and education. Volleyball game is a form of movement, that is, short bursts of physical movement is separated by a short interval of rest. A short period of time, the outbreak of the spike and block is mainly anaerobic lactic acid system for energy. Mainly depends on the volleyball movement from the anaerobic system of energy supply, but from the volleyball match without a time limit to improve the oxygen supply to the same cannot be ignored. The requirement of physical training is too low to take up training time.

\subsection{Single physical training model}

From the biological point of view, the training means and the load has a great influence on the training effect, the choice of training methods and the size of the load determines the effect of physical training. At present, in the physical training of Chinese volleyball coaches, training means is single, the training load also has blindness, for example, during strength training, are often the first bar. The coach 
is not a correct understanding of the methods of strength training, but also through the advanced jump exerciser, dynamic stimulation strength training; to speed training only single speed; for endurance training is the only way of running to track type. The blindness of the physical training load of the volleyball is mainly reflected in the increase of the number of training, so that the body's ability to get no effective stimulation, resulting in the athlete's physical ability is not effectively improved. No matter any movement in the determination of training principles and content, the coaches must first master the rules and characteristics of the project, in order to make the training to achieve a multiplier effect. However, our country has not fully mastered the rules of volleyball now, but also did not fully understand the characteristics of volleyball. The ignorance of the physical ability results the technology of the high level volleyball players cannot work.

\subsection{Unreasonable physical training content}

In terms of kinematics, the general physical training is to ensure the health of the athletes, promote their physical fitness and improve the training. The special physical fitness training requirements of the professional is very strong, is to improve the quality of special sports athletes need to. At present, the deficiency of the physical training of Volleyball in our country is more than the general physical training, and the lack of special physical training. As the basis of special physical ability, the volleyball players will take part in the special physical training when the general physical ability achieves a certain level. However, the physical training methods of the volleyball team in our country are not specific, and all the year round, the result of the general physical training and the special physical training is out of the way. From the point of view of physical training methods, basically every university has adopted several methods of physical training. In terms of the quality of the training process, there are also a variety of results. However, there are still some problems that can be solved in the aspect of fitness training, so that it can promote the integration of physical training and special training more effectively. For example, in terms of training methods, swimming and games and other new physical training methods can be introduced into the physical training. In terms of training effect, it can increase the training time and enrich the way of training, so that a variety of sports qualities have been fully developed.

\section{Countermeasures of Physical Training in Volleyball Training}

\subsection{Increase physical training time}

The coach should put the physical training course in the technical and tactical training. This method combines the characteristics of the high level volleyball team in Colleges and universities not only to save time for physical training, but also to solve the contradiction between learning and training. Part of the coaches will be physical training in technical and tactical training between. This approach 
refers to the physical training after the preload, and then carries out technical and tactical training. This arrangement method can meet the requirements of the competition load to simulate the competition. Two timing arrangements have their own advantages, coaches according to the various stages of the task and requirements of the program, the use of the corresponding physical training arrangements. The physical training can be all-round athlete's strength, stamina, speed, agility and flexibility, improve the athlete sports quality, each organ system function, and make the athletes in various parts of the body get balanced development. General physical training, can improve the physical ability of special sports need to lay the foundation. The physical training does not mean that the various parts of the body, in the process of sports training and sports quality of each organ system to develop and improve the absolute equilibrium, on the contrary, the correct approach is to should be based on specific needs and personal special movement, arranged to have a main belt in time. Only by increasing the physical training time, can we really improve the physical quality of volleyball players to improve the performance of the competition.

\subsection{Enrich physical training models}

The single bar equipment cannot meet the needs of strength training of volleyball players. So, in order to improve the volleyball training, we must strengthen the study on physical training of scientific method, adopt advanced technology and equipment of the science of physical training of athletes is monitored, in order to improve the scientific level of physical training through various forms. In the process of physical training, the students need to be combined with the actual situation, to take a step-by-step teaching process. We should do a good job in training on students' basic ability of the existing system status, the weak students in physical training based on the result, the higher degree of difficulty or strength training, there are often not to adapt to the situation, therefore, need to carry out physical training work based on the basis of. To the actual situation of the students as the starting point to carry out the training work for students, different training content, there are also differences in the ability to grasp, therefore, need to according to the actual situation of students, the physical training to the specific implementation. At present, the high level volleyball teams in colleges and universities are composed of several college students. And the training plan developed by the coaches is usually a long cycle. Therefore, it is feasible and necessary to make a reasonable physical training plan for every athlete. The special training is to pay attention to sports training technical and tactical training, teamwork is of great significance in them, so the demand is not strong, but the physical training is to maximize the movement potential of every athlete, guarantee the effective technical and tactical play. Physical training for coach's need, when necessary, may invite specialized fitness coach to help for suiting measures to local conditions and formulate training plan. 


\subsection{Improve physical training content}

General physical training to improve the athletes' body organ motion ability and motor function, as the amount of training with heavy load and high strength match tamp two foundations: load capacity of aerobic metabolism and neuromuscular system. Basic physical training stage, increase the total load of physical training, and gradually improve the aerobic endurance training intensity for the full year of training in the exercise load to do further pave the special physical training stage. The physical training is mainly for coaches in terms of rationality, the longer overall teaching of volleyball coach in Colleges and universities, teaching experience, in volleyball teaching as the main work, therefore, more research work conditions to participate in physical training and scientific frontier in. The development of sports has always been the social politics, economy and culture, sports and other sports policy form a deep effect, the results from the survey of university high level volleyball team coaches, coaches generally on the basis of the theory of physical training has a certain degree of understanding. The coach's awareness of physical training is the basic situation based on their own experience.

\section{Conclusion}

With the continuous improvement of the level of science and technology, the tactical level of volleyball players is getting higher and higher. However, as the basis of volleyball technology and tactics, the level of physical fitness of athletes is still far from the standard required by the high level competition. This article analyses the present situation of the physical training in the volleyball training to carry on the concrete countermeasures to improve of the volleyball physical training performance.

\section{References}

[1] Zhao Liang, Shen Zhe, Effect of Core Stability Training Program on Special Physical Ability in Youth Volleyball Players, 51(5), pp. 3-10, 2015.

[2] Xie Enli, The Research of Status Quo and Analysis Physical Conditioning Training of Shanghai High Level College Volleyball Teams, Sports Research and Education, 22(3), pp. 74-76, 2007.

[3] Mao Julan, Application Research of Core Strength in the Training of Female Volleyball Athletes in Colleges and Universities, Hubei Sports Science, 35(2), pp. 124-127, 2016.

[4] Zhu Hongbin, Evaluation and training on college student volleyball player, Journal of Foshan University (Natural Sciences Edition), 33(6), pp. 91-96, 2015. 